\title{
Epidemiology of Soybean Rust in Soybean Sentinel Plots in Florida
}

Heather M. Young, Graduate Student, James J. Marois, Professor of Plant Pathology, and David L. Wright, Professor of Agronomy, University of Florida - NFREC, Quincy 32351; Dario F. Narváez, Research Scientist, Monsanto Company, St. Louis, MO 63137; and G. Kelly O'Brien, Biological Scientist, University of Florida - NFREC, Quincy 32351

\begin{abstract}
Young, H. M., Marois, J. J., Wright, D. L., Narváez, D. F., and O’Brien, G. K. 2011. Epidemiology of soybean rust in soybean sentinel plots in Florida. Plant Dis. 95:744-750.

Since its discovery in the southeastern United States in 2004, soybean rust (SBR) has been variable from year to year. Caused by Phakopsora pachyrhizi, SBR epidemics in Florida are important to understand, as they may serve as an inoculum source for other areas of the country. This study examined the first disease detection date, incidence, and severity of SBR in relation to environmental data, growth stage, and maturity group (MG3, MG5, MG7) in soybean sentinel plots $\left(225 \mathrm{~m}^{2}\right)$ across north Florida from 2005 through 2008. The majority (91\%) of the initial infections were observed in MG5 and MG7 soybeans, with

plots not becoming infected until growth stage R4 or later. Precipitation was the principle factor affecting disease progress, where disease increased rapidly after rain events and was suppressed during dry periods. On average, plots became infected 30 days earlier in 2008 than 2005. In 2008, there was a significant increase in disease incidence and severity associated with the occurrence of Tropical Storm Fay, which deposited up to $380 \mathrm{~mm}$ of rainfall in north Florida. The results of this study indicate that climatic and environmental factors are important in determining the development of SBR in north Florida.
\end{abstract}

Phakopsora pachyrhizi Syd. \& P. Syd. causes soybean rust (SBR), one of the most destructive diseases to soybean (Glycine $\max (\mathrm{L}$.) Merrill) production. It has a worldwide distribution, being reported in countries of Asia and Australasia, Uganda, Zimbabwe, Nigeria, South Africa, Paraguay, Argentina, Bolivia, Brazil, Uruguay, Hawaii, and the continental United States $(12,23)$. SBR was first identified in North America in Baton Rouge, LA, on 10 November 2004 (23). SBR can affect soybean yield by reducing seed weight of soybeans by 40 to $80 \%$, reducing shoot weight by $20 \%$, and reducing the overall number of pods per plant and the photosynthetic area (28). Devastating yield losses of up to 60, 63, and $100 \%$, have been reported in recent years from Paraguay, Brazil, and South Africa, respectively (3,29). The impact of yield loss in U.S. commercial fields has been minimal thus far; however, experimental plot losses have ranged from 19 to $35 \%$ in Alabama, Georgia, and Florida $(6,17)$. Before SBR arrival in the continental United States, Yang et al. (27) estimated that yield losses could exceed $10 \%$ in the United States with up to $50 \%$ yield loss in the southeastern states.

The $P$. pachyrhizi life cycle, including spore germination, appressoria formation, leaf penetration and colonization, uredinia development, and sporulation can be completed in 9 days (2). Melching et al. (16) reported that SBR infection requires a minimum of 6 to $7 \mathrm{~h}$ of continuous leaf wetness at a temperature between 18 and $26.5^{\circ} \mathrm{C}$. Marchetti et al. (14) further explained that as the temperature decreases below $18^{\circ} \mathrm{C}$, the length of the dew period needed for infection increases. In field trials in north Florida, Narváez et al. (18) reported that extended periods of leaf wetness $(18 \mathrm{~h})$ increased disease severity and rate of spread of the pathogen in the upper canopy.

Since $P$. pachyrhizi can survive the winter temperatures of the southeastern United States $(16,20)$, it has been hypothesized that the spread of SBR into major soybean producing areas of the U.S. soybean belt is dependent on south-to-north dispersal of viable

Corresponding author: Heather Marie Young,

E-mail: hmarieyoung@ufl.edu

Accepted for publication 17 February 2011.

doi:10.1094/PDIS-07-10-0552

(C) 2011 The American Phytopathological Society urediniospores (10,19). Jurick et al. (13) assessed SBR survival and host availability of kudzu (Pueraria spp.) over winter months in Florida and discovered that naturally senesced kudzu leaves previously infected by $P$. pachyrhizi have the potential to serve as inoculum sources. While kudzu likely provides the initial inoculum for SBR on soybeans, it is the development of the disease within southern commercial soybean fields that provides the inoculum for epidemics in the northern and southern United States (4).

Del Ponte et al. (5) highlighted the importance of precipitation influencing SBR epidemics, especially for regions where temperature is not a limiting factor for disease development, such as Florida. Examples of the importance of precipitation on SBR development include: severe epidemics in high-rainfall areas of the lower Richmond Valley in Australia (24), yield losses of up to $100 \%$ during rainy seasons and only 10 to $15 \%$ losses during a dry season in Thailand (22), and suppressed disease development in Brazil and Paraguay during moderate to severe droughts in the middle to late growing season (29). The objective of this study was to examine environmental and climatic factors that affected SBR development within the soybean sentinel plots of north Florida. It was hypothesized that disease onset and development would be highly correlated with moisture values calculated from the Florida Automated Weather Network.

\section{Materials and Methods}

Sentinel plot data. Beginning in 2005, a national soybean sentinel plot program was established through the Integrated Pest Management - Pest Information Platform for Extension and Education (ipm-PIPE: sbr.ipmpipe.org) (11), to which the data for this study are reported. Data were utilized from 46 soybean sentinel plots (SSP) from 2005 through 2008 from 12 different counties in north Florida. Location of the SSPs was dependent upon agronomic land availability in the counties, and when possible the plots were planted in the same location each year. SSPs that did not get planted within $4.8 \mathrm{~km}$ of the previous year's planting were from the following counties and years: Escambia 2007, Santa Rosa 2006, Okaloosa 2007 and 2008, Walton 2006 and 2008, Holmes 2006, Jackson 2008, Jefferson 2006, Madison 2006, Suwannee 2008, Columbia 2008 (Fig. 1). Seven to 11 different SSPs became infected with SBR each year and were used for analysis. On average, SSPs were planted in a $225 \mathrm{~m}^{2}$ area with $25-\mathrm{cm}$ row spacing. All locations across the years were planted in March or April (Julian date 83-119) to detect SBR at the earliest date it developed 
in the county. Two different maturity group 3 (MG3) varieties, two different MG5 varieties, and three different MG7 varieties were used in SSPs from 2005 through 2008 (Table 1). All varieties used are susceptible to SBR. The SSPs were managed using standard production practices for Florida (26) and were not irrigated.

Data collection. Each SSP was scouted biweekly and then scouted weekly for SBR after one of the following conditions occurred: first bloom of soybean (growth stage R1) (15), presence of SBR in the surrounding counties, forecast or spore deposition data suggested increased risk, or environmental conditions became conducive to SBR development. Scouting consisted of arbitrarily collecting 100 leaflets from each maturity group, so each site had a total of 300 leaflets collected per sampling date. Leaflets collected from each maturity group were placed in three separate plastic bags, stored at room temperature $\left(\sim 25^{\circ} \mathrm{C}\right)$, and evaluated within 1 to 7 days. Maturity group data were recorded individually each year, except in 2005, and SSP data from Santa Rosa County in 2006 where maturity group data were compiled and reported. As such, 2005 data and Santa Rosa County data from 2006 were omitted when analyzing maturity group data.

Disease severity was determined using a dissecting microscope for symptomatic leaf area on individual leaflets. An arbitrary rating scale was used with the following values and corresponding severity ranges based on a visual key developed by Bayer Crop Science (Kansas City, KS): $0=$ no disease, $1=$ up to $2.5 \%, 2=2.5$ to $5 \%, 3$ $=5$ to $10 \%, 4=10$ to $15 \%, 5=15$ to $25 \%, 6=25$ to $35 \%, 7=35$ to $67.5 \%$, and $8=67.5$ to $100 \%$ of the leaf area affected by SBR. The following midpoint rating was used to create severity values: 0 $=0 \%, 1=1.25 \%, 2=3.75 \%, 3=7.5 \%, 4=12.5 \%, 5=20 \%, 6=$ $30 \%, 7=51.25 \%$, and $8=83.75 \%$. Incidence and severity data for each individual MG was averaged for each sampling date, and this average was used to calculate weekly and yearly averages. Maximum incidence and severity values for each SSP were averaged to determine yearly maximum incidence and severity, regardless of date (Table 1). Incidence and severity values were aligned chronologically and used to obtain the area under the disease progress curve (AUDPC) (Table 1, Fig. 2). The previous year's maximum incidence and severity data used was in reference to the year being analyzed (i.e., when analyzing Jefferson SSP 2006 maximum incidence data, the previous year's maximum incidence-Jefferson SSP 2005 maximum incidence data—was used). SSP 2005 data did not have any previous year's maximum incidence and maximum severity to use in analysis (i.e., no data was recorded in 2004). In the circumstance where a SSP did not become infected, 0 was used for that year's maximum incidence and severity. In such a case, if a SSP did not become infected until 2007, there would only be previous year's maximum incidence and severity data for 2008. In the event the SSP was lost due to poor germination or deer damage, these data were omitted.

The duration of the epidemic was calculated from the week of first detection to the week of maximum severity (Table 1). Average incidence and severity were plotted over time (Fig. 2), and the AUDPC was calculated using the formula:

$\mathrm{AUDPC}=\sum_{i=1}^{n} \frac{\left(x_{i+1}+x_{i}\right)}{2}\left(t_{t+1}-t_{i}\right)$

where $x_{i}=$ proportion of tissue affected (disease severity) at the $i$ th observation, $t=$ time (days), and $n=$ total number of observations. $\sum$ is the sum of areas of all of the individual trapezoids or areas from $i$ to $n-1$. $i$ and $i+1$ represent observations from 1 to $n$.

Julian days were used for date calculations, where 1 January is Julian day 1 . Yearly disease incidence and severity averages, discussed previously, were used to calculate the AUDPC for each year. AUDPC was calculated through the second week in September each year based on natural senescence of plots (Fig. 2).

The apparent infection rate per week for each year was calculated from weekly severity averages from the week of detection to the week of maximum severity; these were also averaged together to get average infection rate per year for the duration of the epidemic (Table 1). Apparent infection rate was calculated using:

$r=\left(\frac{1}{t_{2}-t_{1}}\right) \ln \left[\frac{x_{2}\left(1-x_{1}\right)}{x_{1}\left(1-x_{2}\right)}\right]$

where $t$ is time during which infection has occurred, $x$ is disease severity, and "In" is the natural logarithm. Disease severity at time $t_{1}=x_{1}$ (disease severity at first disease detection) and disease severity at time $t_{2}=x_{2}$ (disease severity when maximum severity is reached).

Six climatic time periods were used for analysis: 2,3 , and 4 weeks before disease detection (including first week of detection) and 4,6 , and 8 weeks before maximum incidence and severity. These time periods were used to correlate preceding environmental conditions with first disease detection, maximum incidence, and maximum severity. The Florida Automatic Weather Network stations (FAWN) were utilized to obtain environmental data collected

B

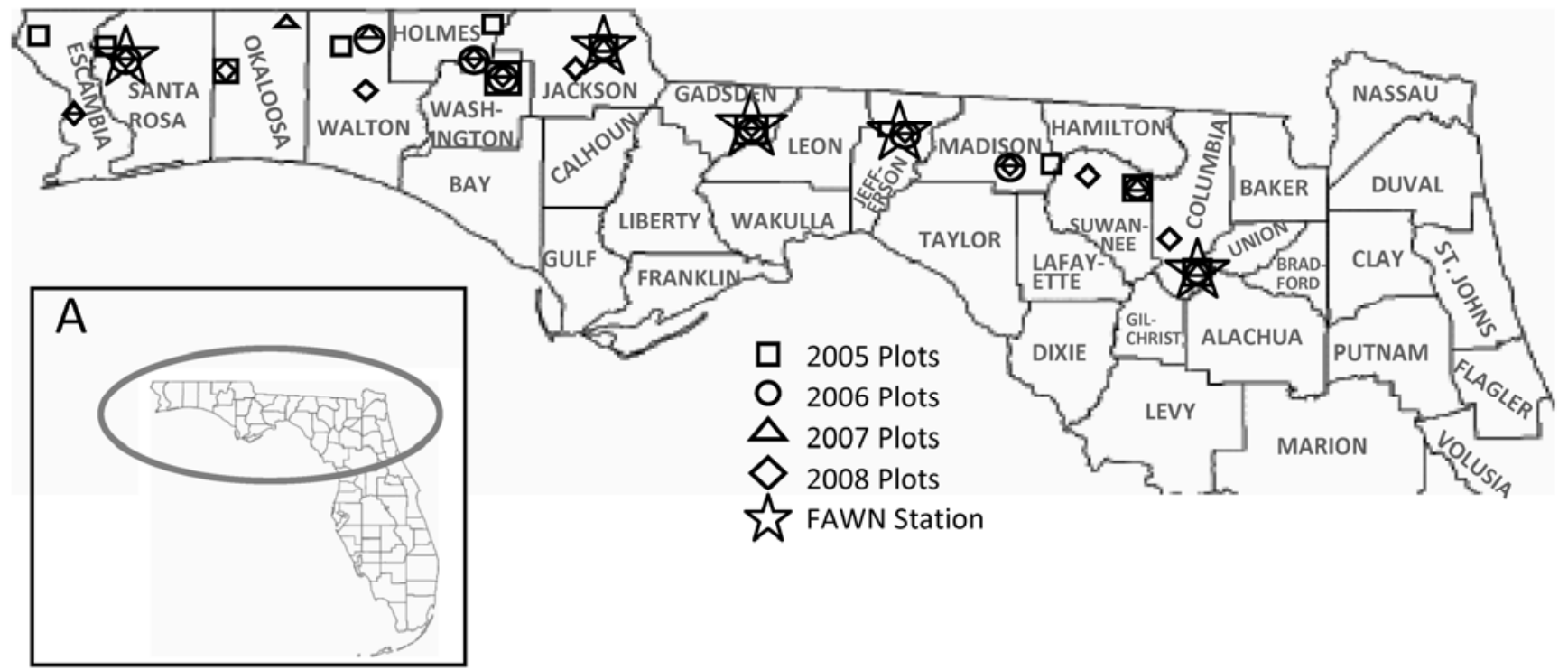

Fig. 1. A, Florida map indicating, with the circle, the study area of north Florida. B, Enlarged area of north Florida with approximate locations of soybean sentinel plots from 2005 to 2008 used to monitor soybean rust and Florida Automated Weather Network (FAWN) stations that were used to obtain environmental data utilized in this study. 
from five counties in the Florida Panhandle (Escambia, Jackson, Gadsden, Jefferson, and Suwannee) (Fig. 1). Weekly average temperatures were calculated from the daily average air temperatures from FAWN stations, recorded at $60 \mathrm{~cm}$ above the soil. Similarly, the weekly average relative humidity ( $\mathrm{RH} \%)$, solar radiation (watts per square meter), and precipitation $(\mathrm{mm})$ were calculated from FAWN stations at $2 \mathrm{~m}$ above soil level, and soil temperature was taken at $10 \mathrm{~cm}$ below soil surface. These weekly averages were used to create the yearly averages presented in Figure 2. The dew point was calculated from the daily average air temperature and $\mathrm{RH}$ using the following equations:

$T_{d}=\frac{[b * \alpha(T, R H)]}{[a * \alpha(T, R H)]}$

where $\alpha(T, R H)=(a * T) /(b+T)+\ln (R H)$, where $T$ is temperature in degrees Celsius, $\mathrm{RH}$ is the measured relative humidity, $T_{d}$ is the calculated dew point temperature $\left({ }^{\circ} \mathrm{C}\right)$, and " $\mathrm{ln}$ " refers to the natural logarithm. The constants are: $\mathrm{a}=17.27$ and $\mathrm{b}=237.7\left({ }^{\circ} \mathrm{C}\right)$. The uncertainty in the measured dew point temperature is a function of the measured temperature and relative humidity and the uncertainties associated with those measurements. The uncertainty in the calculated dew point temperature is $\pm 0.4^{\circ} \mathrm{C}$. This expression is based on the "Magnus" (or "Magnus-Tetens") approximation for the saturation vapor pressure of water in air as a function of temperature (1). It is considered valid for $0^{\circ} \mathrm{C}<T<60^{\circ} \mathrm{C} ; 1 \%<\mathrm{RH}<$ $100 \% ; 0^{\circ} \mathrm{C}<T_{d}<50^{\circ} \mathrm{C}$.

Dew point temperatures were then compared with the hourly average air temperature, and hours where the difference between the two variables was 0 to 2 were counted as dew leaf wetness hours for daily calculations (8). Daily leaf wetness hours were averaged over the different time periods. The number of days with $>0 \mathrm{~mm},>1 \mathrm{~mm}$, and $>5 \mathrm{~mm}$ of precipitation and cumulative precipitation were recorded for each time period in question using FAWN data. All variables utilized in this study are listed in Table 2.

Data analysis. Statistical analyses were performed using SAS version 9.1 (SAS Institute, Inc., Cary, NC). The PROC CORR procedure of SAS was used to conduct Pearson's correlation test. Correlations were examined between first detection date of SBR and weekly average air temperature, soil temperature, relative humidity, solar radiation, precipitation, daily leaf wetness hours, number of days with precipitation $>0 \mathrm{~mm},>1 \mathrm{~mm}$, and $>5 \mathrm{~mm}$, the number of years a site was previously infected, and sites' previous maximum incidence and severity. Each site's first disease detection date in each year was correlated with climatic variables averaged over 2, 3, and 4 weeks prior to detection date (including week of detection). Pearson's correlation test was also used to examine the

Table 1. Data summary of north Florida soybean sentinel plot (SSP) records and the soybean rust epidemic data within those plots from 2005 through 2008

\begin{tabular}{|c|c|c|c|c|}
\hline & 2005 & 2006 & 2007 & 2008 \\
\hline Variety planted $^{\mathrm{a}}$ & $\begin{array}{l}\text { MG3-DP 3861RR } \\
\text { MG5-DP 5915RR } \\
\text { MG7-DP 7870RR }\end{array}$ & $\begin{array}{l}\text { MG3-HS 3456RR } \\
\text { MG5-DP 5915RR } \\
\text { MG7-DP 7220RR }\end{array}$ & $\begin{array}{l}\text { MG3-HS 3861RR } \\
\text { MG5-DP 5915RR } \\
\text { MG7-DP 7220RR }\end{array}$ & $\begin{array}{l}\text { MG3-DP 3861RR } \\
\text { MG5-AG 5905RR } \\
\text { MG7-DP 7330RR }\end{array}$ \\
\hline Total number of SSP & 12 & 10 & 12 & 12 \\
\hline Number of SSP infected & 7 & 7 & 11 & 11 \\
\hline $\mathrm{AUDPC}^{\mathrm{b}}\left(\mathrm{SEV}^{\mathrm{c}}\right)$ & 146 & 39 & 20 & 204 \\
\hline $\operatorname{AUDPC}\left(\mathrm{INC}^{\mathrm{d}}\right)$ & 19 & 4 & 4 & 21 \\
\hline Plant date in Julian day & 83 & 88 & 94 & 99 \\
\hline First disease detection in Julian day & 231 & 258 & 243 & 216 \\
\hline Days after planting disease was detected in Julian day & 148 & 170 & 148 & 115 \\
\hline Duration (days) & 24 & 33 & 34 & 58 \\
\hline Avg. max. severity (\%) & 9 & 11 & 4 & 15 \\
\hline Avg. max. incidence (\%) & 82.4 & 63.5 & 52.4 & 83.1 \\
\hline Avg. apparent infection rate & 0.22 & 0.11 & 0.17 & 0.24 \\
\hline
\end{tabular}

a Abbreviations for varieties planted: $\mathrm{MG}=$ maturity group, $\mathrm{RR}=$ roundup ready, $\mathrm{DP}=$ Delta and Pine Land seed, $\mathrm{HS}=\mathrm{Hyland}$ Seed, $\mathrm{AG}=\mathrm{Asgrow}$ seed.

${ }^{\mathrm{b}}$ AUDPC $=$ area under the disease progress curve.

${ }^{\mathrm{c}} \mathrm{SEV}=$ disease severity.

${ }^{\mathrm{d}} \mathrm{INC}=$ disease incidence.

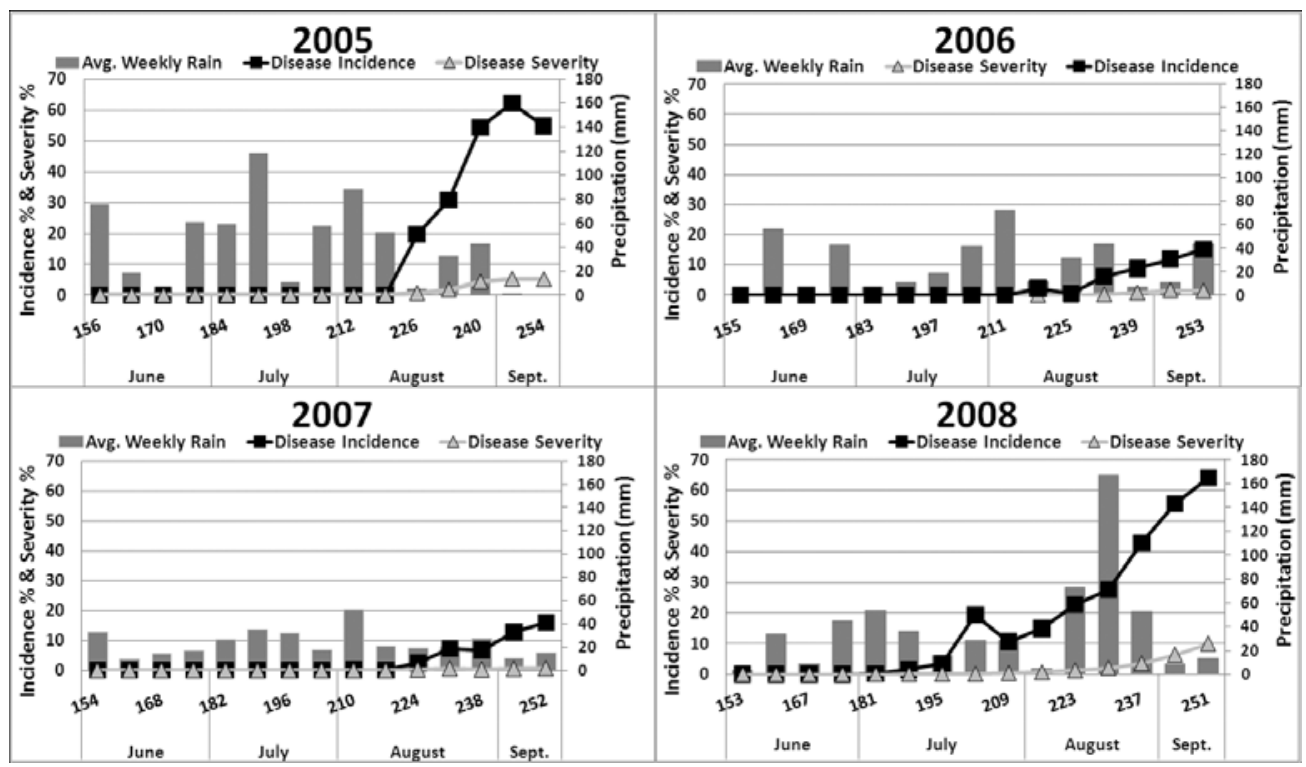

Fig. 2. Disease incidence (square symbol, primary y-axis) and severity (triangle symbol, primary y-axis) of soybean rust, and weekly cumulative rain (bars, secondary y-axis) were averaged across soybean sentinel plot locations in north Florida and plotted over time (in Julian days, x-axis) during the seasons 2005 through 2008. 
correlations between SBR maximum incidence and severity (percentage), first detection date, weekly average air temperature, soil temperature, relative humidity, solar radiation, precipitation, daily leaf wetness hours, number of days with precipitation $>0 \mathrm{~mm},>1$ $\mathrm{mm}$, and $>5 \mathrm{~mm}$, the number of years a site was previously infected, and the site's previous maximum incidence and severity. Maximum incidence and severity for each site and year was correlated with climatic variables averaged over 4,6 , and 8 weeks prior to a site's maximum incidence and severity.

\section{Results}

All correlations were significant with a $P$ value less than 0.05 . Significant correlations between climatic variables and first detection date of SBR, maximum incidence, and maximum severity are listed in Tables 3, 4, and 5; variables not listed were nonsignificant. Heavy rainfall $(>80 \mathrm{~mm}$ ) occurred during 2005 and 2008, with earlier disease detection and higher maximum incidences and severities. In contrast, dry to drought conditions $(<80 \mathrm{~mm}$ of total rain) occurred during 2006 and 2007, with later disease detection and lower maximum incidences and severities (Fig. 2). Disease duration (time period from first detection to maximum severity) increased from 2005 through 2008, while AUDPC, first disease detection, and maximum incidence and severity varied between years (Table 1). Five sentinel plots in 2005 and one in 2007 and 2008 were lost due to poor germination or deer damage before infection could occur, and in 2006 three sentinel plots never became infected. The majority of SSPs (33 plots) did not become infected with SBR until growth stage R4 or later; however, two SSPs were infected by growth stage R2, and one SSP was infected by growth stage R3 (15) (Fig. 3). In SSPs from 2006 through 2008, SBR infections were first discovered in MG3, MG5, and MG7 a total of 4, 17, and 14 times, respectively (Table 6).

First disease detection was significantly correlated with the number of years a site had been infected $(-0.35)$, previous year's maximum incidence $(-0.49)$, planting date $(-0.34)$, and maximum incidence and severity ( -0.66 and -0.44 , respectively) (Table 3$)$. Environmental variables to which first disease detection were negatively correlated included the number of days with greater than 0 $\mathrm{mm}$ and $1 \mathrm{~mm}$ precipitation ( -0.39 and -0.49 , respectively), cumulative solar radiation $(-0.54)$, and average leaf wetness $(-0.53)$ during the 4-week time period prior to first disease detection (Ta-

Table 2. Description of variables used to examine the relationship between soybean rust first disease detection, maximum disease incidence, severity, and environmental conditions in north Florida soybean sentinel plots from 2005 through 2008

\begin{tabular}{|c|c|}
\hline Variable & Description \\
\hline Onset & First disease detection date \\
\hline MaxIncid & $\begin{array}{l}\text { Maximum disease incidence }(\%) \text { reached at a } \\
\text { particular site and year }\end{array}$ \\
\hline MaxSev & $\begin{array}{l}\text { Maximum disease severity }(\%) \text { reached at a } \\
\text { particular site and year }\end{array}$ \\
\hline Planting date & Date planting occurred \\
\hline PrevYRMaxSev & Previous year's maximum disease severity (\%) \\
\hline PrevYRMaxIncid & Previous year's maximum disease incidence $(\%)$ \\
\hline NumyrInf & Number of years site was previously infected \\
\hline InfectRate & $\begin{array}{l}\text { Infection rate calculated using initial and maximum } \\
\text { disease severity }\end{array}$ \\
\hline AvgRain $^{\mathrm{a}}$ & Average precipitation $(\mathrm{mm})$ \\
\hline $\mathrm{RD}>0 \mathrm{~mm}^{\mathrm{a}}$ & Number of days with precipitation $>0 \mathrm{~mm}$ \\
\hline $\mathrm{RD}>1 \mathrm{~mm}^{\mathrm{a}}$ & Number of days with precipitation $>1 \mathrm{~mm}$ \\
\hline $\mathrm{RD}>5 \mathrm{~mm}^{\mathrm{a}}$ & Number of days with precipitation $>5 \mathrm{~mm}$ \\
\hline SolRad $^{\mathrm{a}}$ & Cumulative solar radiation $\left(\mathrm{W} / \mathrm{m}^{2}\right)$ \\
\hline AvgTemp ${ }^{a}$ & Average air temperature at $60 \mathrm{~cm}$ height \\
\hline AvgSoilTemp ${ }^{a}$ & Average soil temperature at $10 \mathrm{~cm}$ depth \\
\hline $\mathrm{RH}^{\mathrm{a}}$ & Average relative humidity \\
\hline LeafWetAvg ${ }^{a}$ & Average of leaf wetness hours \\
\hline
\end{tabular}

${ }^{a}$ Each variable was determined for each of the six time periods of climate examined: 2, 3, and 4 weeks before first disease detection (including first week of detection) and 4, 6, and 8 weeks before maximum incidence and severity were achieved. ble 3). Temperature and relative humidity did not have a significant correlation with first disease detection.

Maximum disease incidence significantly decreased 23 and $17 \%$, and increased $59 \%$, in 2006, 2007, and 2008, respectively, in comparison with maximum incidence the previous year (Table 1). Maximum incidence had a significant positive correlation with average weekly precipitation $(0.39)$ for the 8 -week period prior to maximum incidence date (Table 4). Maximum severities increased $22 \%$, decreased $64 \%$, and increased $275 \%$ in 2006, 2007, and 2008 , respectively, in comparison with the maximum severity of the previous year (Table 1). Climatic variables that significantly correlated with maximum severity included average weekly precipitation (0.38) and average leaf wetness $(0.37) 4$ weeks prior to maximum severity date. Cumulative solar radiation 4 weeks prior to maximum severity date was weakly correlated with maximum severity $(P$ value 0.0417 and correlation coefficient -0.35 ) (Table 5). Plotting cumulative precipitation $(\mathrm{mm})$ recorded 4 weeks prior to maximum severity date and the maximum severity (\%) from 2005 through 2008 revealed a threshold of $300 \mathrm{~mm}$ cumulative precipitation (Fig. 4).

\section{Discussion}

This study examined the epidemic development of SBR from 2005 through 2008. Epidemic development was correlated to

Table 3. Variables correlated, using Pearson's correlation coefficient, with first disease detection of soybean rust during growing seasons 2005 through 2008 in soybean sentinel plots in north Florida

\begin{tabular}{|c|c|c|}
\hline \multirow[b]{2}{*}{ Variable } & \multicolumn{2}{|c|}{ Onset $^{\mathbf{a}}$} \\
\hline & $P$ value & Correlation coefficient \\
\hline MaxIncid ${ }^{b}$ & $<0.0001$ & -0.66 \\
\hline $\mathrm{MaxSev}^{\mathrm{c}}$ & 0.0080 & -0.44 \\
\hline Planting date & 0.0434 & -0.34 \\
\hline PrevYRMaxIncid ${ }^{d}$ & 0.0048 & -0.49 \\
\hline NumyrInfe & 0.0381 & -0.35 \\
\hline $\mathrm{RD}>0 \mathrm{~mm} 4 \mathrm{wks}^{\mathrm{f}}$ & 0.0193 & -0.39 \\
\hline $\mathrm{RD}>1 \mathrm{~mm} 4 \mathrm{wks}^{\mathrm{g}^{*}}$ & 0.0026 & -0.49 \\
\hline SolRad $2 w_{k s}^{h}$ & 0.0025 & -0.49 \\
\hline SolRad $3 w_{k s}{ }^{i}$ & 0.0007 & -0.54 \\
\hline SolRad $4 \mathrm{wks}^{\mathrm{j}^{*}}$ & 0.0006 & -0.54 \\
\hline LeafWetAvg 4wks ${ }^{k^{*}}$ & 0.0009 & -0.53 \\
\hline
\end{tabular}

${ }^{\text {a }}$ Onset $=$ first disease detection date.

${ }^{\mathrm{b}}$ MaxIncid = maximum disease incidence $(\%)$ at a particular site and year.

${ }^{\mathrm{c}} \mathrm{MaxSev}=$ maximum disease severity $(\%)$ at a particular site and year.

${ }^{\mathrm{d}}$ PrevYRMaxIncid = previous year's maximum disease incidence $(\%)$.

${ }^{\mathrm{e}}$ NumyrInf $=$ number of years site was previously infected.

${ }^{\mathrm{f}} \mathrm{RD}>0 \mathrm{~mm} 4 \mathrm{wks}=$ number of days with precipitation $>0 \mathrm{~mm}$, over 4 weeks prior to first disease detection date.

g $\mathrm{RD}>1 \mathrm{~mm} 4 \mathrm{wks}=$ number of days with precipitation $>1 \mathrm{~mm}$, over 4 weeks prior to first disease detection date.

${ }^{\mathrm{h}}$ SolRad $2 \mathrm{wks}=$ cumulative solar radiation $\left(\mathrm{W} / \mathrm{m}^{2}\right)$, over 2 weeks prior to first disease detection date.

${ }^{i}$ SolRad $3 \mathrm{wks}=$ cumulative solar radiation $\left(\mathrm{W} / \mathrm{m}^{2}\right)$, over 3 weeks prior to first disease detection date.

j SolRad $4 \mathrm{wks}=$ cumulative solar radiation $\left(\mathrm{W} / \mathrm{m}^{2}\right)$, over 4 weeks prior to first disease detection date.

${ }^{\mathrm{k}}$ LeafWetAvg $4 \mathrm{wks}=$ average of leaf wetness hours, over 4 weeks prior to first disease detection date. ${ }^{*}=$ Most significant climatic variables correlated.

Table 4. Variables correlated, using Pearson's correlation coefficient, with maximum incidence of soybean rust during growing seasons 2005 through 2008 in soybean sentinel plots in north Florida

\begin{tabular}{lcc}
\hline & \multicolumn{2}{c}{ Maximum incidence } \\
\cline { 2 - 3 } Variables & $\boldsymbol{P}$ value & Correlation coefficient \\
\hline MaxSev $^{\mathrm{a}}$ & $<0.0001$ & 0.70 \\
${\text { AvgRain } 8 \mathrm{wks}^{\mathrm{b}}}$ & 0.0196 & 0.39 \\
\hline
\end{tabular}

${ }^{\mathrm{a}} \mathrm{MaxSev}=$ maximum disease severity (\%)at a particular site and year.

${ }^{\mathrm{b}}$ AvgRain8wks $=$ average precipitation $(\mathrm{mm})$, over 8 weeks prior to maximum incidence date. 
multiple environmental variables with important trends apparent between the first detection of SBR and the plant descriptor variables of growth stage and maturity group. While SBR can infect soybean at any growth stage, it has been indicated that earlier SBR infections within a growing season increase the chances of yield loss due to higher disease incidence and severity (28). Rarely did SBR infection occur on MG3 soybeans before the other varieties or before the MG3 soybeans reached growth stage R8 (full maturity) (Table 6, Fig. 3). Most often, MG5 and MG7 soybean varieties were first detected with SBR, and at a range of growth stages including R2 (full bloom) through R8 (full maturity) (Table 6, Fig. 3 ). The majority of SSPs were in growth stage R4 (full pod) or later when SBR was first detected (Fig. 3), even though MG3 varieties were at reproductive stages earlier in the year. Hence, soybeans did not become infected at earlier growth stages, most

Table 5. Variables correlated, using Pearson's correlation coefficient, with maximum severity of soybean rust during growing seasons 2005 through 2008 in soybean sentinel plots in north Florida

\begin{tabular}{lrc}
\hline & \multicolumn{2}{c}{ Maximum severity } \\
\cline { 2 - 3 } Variables & P value & Correlation coefficient \\
\hline MaxIncid & $<0.0001$ & 0.70 \\
AvgRain 4 wks & 0.0256 & 0.38 \\
SolRad 4 wks & 0.0417 & -0.35 \\
LeafWetAvg 4 wks & 0.37 \\
\hline
\end{tabular}

${ }^{\text {a }}$ MaxIncid $=$ maximum disease incidence $(\%)$ at a particular site and year.

${ }^{\mathrm{b}}$ AvgRain $4 \mathrm{wks}=$ average precipitation $(\mathrm{mm})$, over 4 weeks prior to maximum severity date.

${ }^{\mathrm{c}}$ SolRad $4 \mathrm{wks}=$ cumulative solar radiation $\left(\mathrm{W} / \mathrm{m}^{2}\right)$, over 4 weeks prior to maximum severity date.

${ }^{\mathrm{d}}$ LeafWetAvg 4 wks = average of leaf wetness hours, over 4 weeks prior to maximum severity date. likely due to lack of inoculum and/or conducive environmental conditions.

From 2006 through 2008, fluctuating first disease detection was correlated with the previous number of years a site had been infected and the previous year's maximum incidence, suggesting that accumulated inoculum could contribute to first disease detection. While first disease detection was negatively correlated with planting date, this might be attributed to other factors over time, such as accumulated inoculum, in that the planting dates were slightly later each year (Table 1). First disease detection data were also strongly correlated with maximum incidence and severity, which can be expected, because with earlier disease onset, greater maximum incidence and severity can be achieved and at an earlier date.

The environmental variables most strongly correlated to SBR first detection were precipitation greater than $1 \mathrm{~mm}$, cumulative solar radiation intensity, and average leaf wetness calculated over the 4-week period prior to SBR detection (Table 3). Although temperature and relative humidity were not directly correlated with first disease detection, the significant correlations of calculated leaf wetness provide an indirect correlation of these variables. The observed correlations with first disease detection imply that days with greater than $1 \mathrm{~mm}$ of precipitation, increased leaf wetness hours, and decreased solar radiation promote earlier disease onset. This concurs with reports by Melching et al. (16) and Narváez et al. (18) that an increase in moisture increased SBR disease intensity. However, the lack of a correlation between first disease detection and the number of days with greater than $5 \mathrm{~mm}$ of precipitation may be explained by the observation that subsequent rainfall for a 30-min period can remove up to $91 \%$ of urediniospores from soybean leaves (7). Furthermore, the correlation between first disease detection and solar radiation coincides with the Isard et al. (9) report that the proportion of $P$. pachyrhizi spores that germinate decreases with increasing exposure to solar radiation.

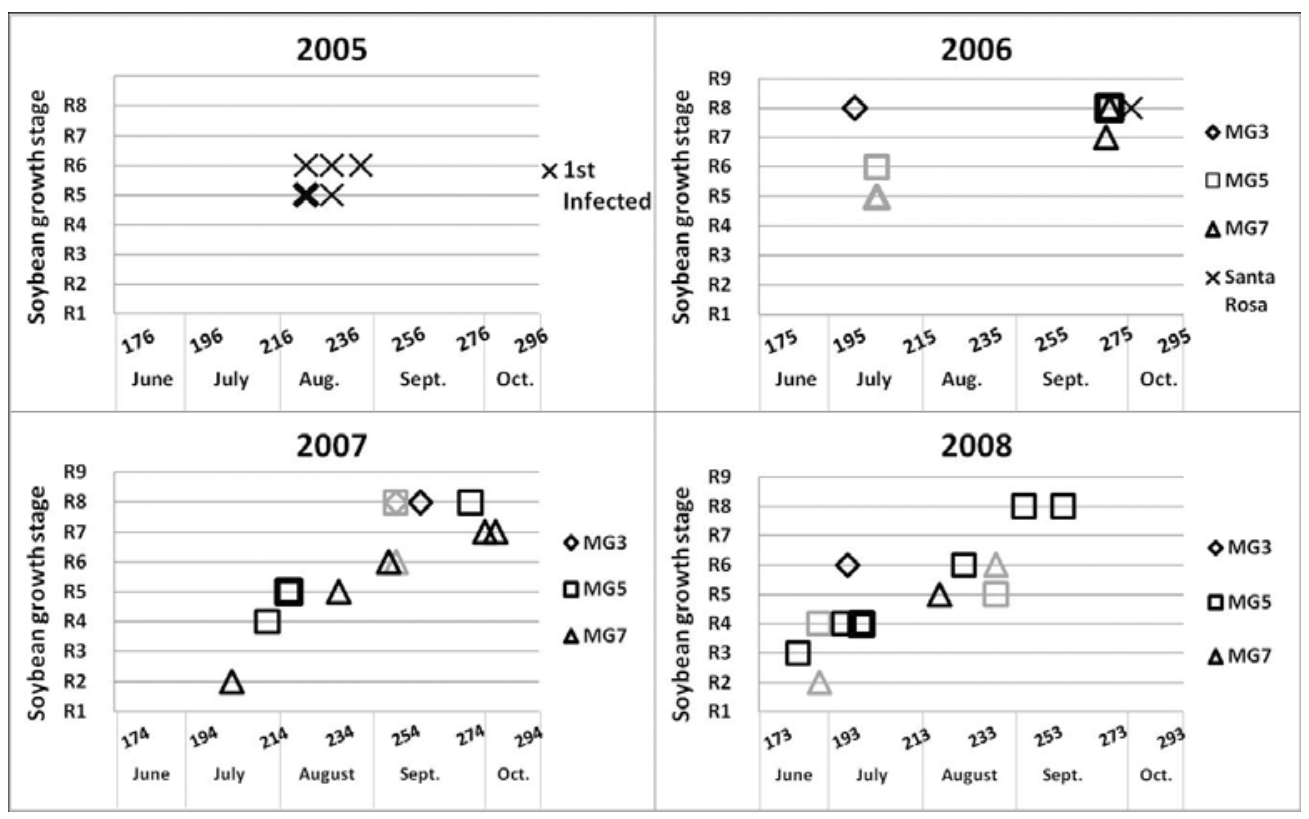

Fig. 3. Soybean growth stage and maturity group (MG) data are plotted over time (in Julian days) for each soybean sentinel plot's (SSP) first detection of soybean rust during the seasons 2005 through 2008. Soybean MG was not recorded for 2005 SSPs or Santa Rosa SSP in 2006, only soybean growth stage is reported in this figure for these data. In 2005, 3 of the 7 SSPs were first detected with SBR at growth stage R5 on 15 August (Julian day 227). The bold "x" on the 2005 graph represents those 3 SSP data. In 2006, 1 out of 7 SSPs were first detected with SBR on MG5 and MG7 on 27 July (Julian date 208) at growth stages R6 and R5, respectively. The gray "square" and "triangle" on the 2006 graph represent that 1 SSP datum. Two other SSP in 2006 were first detected with SBR on MG5 and MG7 on 28 September (Julian date 271) all at growth stage R8; and 1 other SSP was first detected with SBR on 28 September (Julian ate 271) at growth stage R8. The bold "square" and the "triangle" within that square on the 2006 graph represents these 3 SSP data. In 2007, 2 out of 11 SSPs were first detected with SBR on MG5 on 8 August (Julian date 220), both at growth stage R5. The bold "square" on the 2007 graph represents those 2 SSP data. One other SSP in 2007 was first detected with SBR on MG3, MG5, and MG7 on 7 September (Julian date 250) at growth stages R8, R8, and R6, respectively. The gray "square" with the gray "diamond" within it and the gray "triangle" directly below them on the 2007 graph represent that SSP datum. In 2008, 1 out of 11 SSPs was first detected with SBR on MG5 and MG7 on 8 July (Julian date 190) at growth stages R4 and R2, respectively. Another SSP in 2008 was first detected with SBR on MG5 and MG7 on 27 August (Julian date 240) at growth stages R5 and R6, respectively. The gray squares and gray triangles aligned vertically on the 2008 graph represent these SSP data. Two other SSP in 2008 were first detected with SBR on MG5 on 20 July (Julian date 202) at growth stage R4. The bold square on the 2008 graph represents those 2 SSP data. 
Environmental conditions, such as periods of high moisture and low solar radiation, can occur throughout the soybean growing season in Florida during hurricanes and tropical storms. For example, on 10 July 2005, Hurricane Dennis made landfall on Santa Rosa Island in north Florida and resulted in substantial amounts of precipitation $(\max =118 \mathrm{~mm})$ across the north Florida area. The environmental conditions created by Hurricane Dennis could account for the 2005 average disease detection date of 19 August (Julian day 231) being earlier than the following years of 2006 and 2007, which had dry to drought conditions. Notably, precipitation is a readily available variable throughout many regions across the United States, and the correlation of first disease detection with precipitation can be used to determine areas that will become infected after possible spore deposition events.

Del Ponte et al. (5) demonstrated that accumulated precipitation from the month following when SBR was initially detected could be used as a predictor for final disease severity. Similarly, in this study, we found maximum incidence and severity correlated with average precipitation prior to maximum incidence and severity dates. In particular, maximum incidence correlated with average precipitation over 8 weeks prior to maximum incidence date (Table 4 ), whereas maximum severity was most significantly correlated to the average precipitation over 4 weeks prior to maximum severity date (Table 5). The positive correlation of maximum incidence with precipitation over an 8-week time period suggests that incidence is influenced more than maximum severity by precipitation events occurring prior to disease onset. Hurricane Dennis's precipitation may account for not only the early disease onset, but also a greater average maximum incidence in 2005 as compared to 2006 and 2007. In addition, the greatest maximum incidence and severity averages in 2008 may be attributed to the environmental conditions resulting from Tropical Storm Fay, which traveled across north Florida 17 to 24 August and accounted for the peak of average precipitation during the third week in August (Julian day 230) (Fig. 2). The greatest maximum severity and precipitation occurred

Table 6. Number of soybean sentinel plots (SSPs) in which a maturity group was first detected with soybean rust (SBR) from 2006, 2007, and 2008

\begin{tabular}{lcccc}
\hline & \multicolumn{4}{c}{ Maturity group first detected with SBR } \\
\cline { 2 - 5 } & MG3 & MG5 & MG7 & Total diseased SSPs/year \\
\hline 2006 & 1 & $4^{\mathrm{a}}$ & $4^{\mathrm{a}}$ & $6^{\mathrm{b}}$ \\
2007 & $2^{\mathrm{c}}$ & $4^{\mathrm{c}}$ & $7^{\mathrm{c}}$ & 11 \\
2008 & 1 & $9^{\mathrm{d}}$ & $3^{\mathrm{d}}$ & 11 \\
Total & 4 & 17 & 14 & \\
\hline
\end{tabular}

a At 3 SSPs, both MG5 and MG7 were detected with SBR at the same date.

${ }^{\mathrm{b}}$ Only 6 of the 7 SSPs in 2006 had maturity group data reported and used in this study.

${ }^{c}$ At 1 SSP, all 3 maturity groups were detected with SBR at the same date.

${ }^{\mathrm{d}}$ At 2 SSPs, both MG5 and MG7 were detected with SBR at the same date.

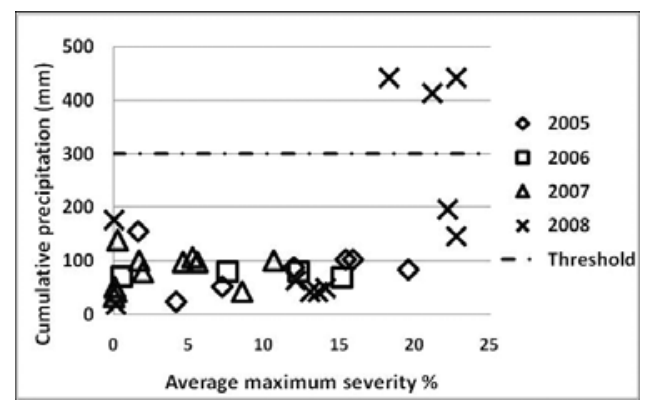

Fig. 4. Precipitation threshold for average maximum disease severity of soybean rust in soybean sentinel plots (SSP) recorded from 2005 through 2008. Symbols represent each SSP average maximum disease severity, as a percentage, reached each year and cumulative precipitation $(\mathrm{mm})$ over the 4 weeks prior to each site reaching maximum disease severity each year (different symbols representing each year); and the line is the threshold at $300 \mathrm{~mm}$ of precipitation. in 2008, indicating that rain, after initial infection, can contribute to the severity of a SBR epidemic in north Florida and that relatively dry to drought conditions, observed in 2006 and 2007, can reduce the maximum severity reached during a growing season (Fig. 2).

Accumulated precipitation 4 weeks prior to maximum severity displays a threshold of $300 \mathrm{~mm}$ of cumulative precipitation (Fig. 4); where average maximum severity was 20.8 and $9.8 \%$ if precipitation was more and less than $300 \mathrm{~mm}$, respectively. Similarly, Del Ponte et al. (5) found thresholds in rainfall correlating to SBR severity in Brazil during the 1-month period after disease detection, where severity was $>70 \%$ and $<30 \%$ if rainfall ranged between 250 and $459 \mathrm{~mm}$, and 10 and $125 \mathrm{~mm}$, respectively.

Compounding factors contributed to fluctuating first disease detection, maximum incidence and severity from 2005 to 2008 in north Florida soybean sentinel plots. These factors include, but are not limited to, varying levels of initial inoculum, leaf wetness hours, and amount of precipitation before and after infection. Correlations between climatic variables and maximum incidence and severity imply that certain environmental conditions are favorable for SBR and may allow the pathosystem to reach a maximum impact earlier in the season. Furthermore, correlation between early disease detection and early maximum incidence and severity reached may lead to earlier available inoculum contributing to rust epidemics in the major soybean regions in the United States. This study indicates that improved prediction of SBR epidemic severity and understanding of the variability of epidemics from year to year in the United States can be gained from continued research and monitoring of SBR in the southeastern United States, as we have yet to see the maximum potential of a SBR epidemic.

\section{Acknowledgments}

This research was supported by funds from the North Central Soybean Research Program. We thank Julie Golod and those who helped with data collection and analysis of soybean sentinel plots.

\section{Literature Cited}

1. Barenbrug, A. W. T. 1974. Psychrometry and Psychrometric Charts, 3rd ed Cape and Transvaal Printers Ltd., Cape Town, S.A

2. Bromfield, K. R. 1984. Soybean rust. Monogr. 11. American Phytopathological Society, St. Paul, MN.

3. Caldwell, P., and Laing, M. 2002. Soybean rust - A new disease on the move. Southern African Society for Plant Pathology Monthly Feature. March 2002. Online publication.

4. Christiano, R. S. C., and Scherm, H. 2007. Quantitative aspects of the spread of Asian soybean rust in the Southeastern United States, 2005 to 2006. Phytopathology 97:1428-1432.

5. Del Ponte, E. M., Godoy, C. V., Li, X., and Yang, X. B. 2006. Predicting severity of Asian soybean rust epidemics with empirical rainfall models. Phytopathology 96:797-803.

6. Delaney, D. P., Lawrence, K. S, Sikora, E. J., Lawence, G. W., Delaney, M. A., and Pegues, M. D. 2007. Efficacy of foliar fungicides for Asian soybean rust disease management and yield enhancement in Alabama. Proc. 2007 National Soybean Rust Symposium online.

7. Dufault, N. S., Isard, S. A., Marois, J. J., and Wright, D. L. 2010. Removal of Wet Deposited Phakopsora pachyrhizi Urediniospores from Soybean Leaves by Subsequent Rainfall. Plant Dis. 94:1336-1340.

8. Gates, D. M. 1968. Transpiration and Leaf Temperature. Annu. Rev. Plant Physiol. 19:211-238.

9. Isard, S. A., Dufault, N. S., Miles, M. R., Hartman, G. L., Russo, J. M., de Wolf, E. D., and Morel, W. 2006. The effect of solar irradiance on the mortality of Phakopsora pachyrhizi urediniospores. Plant Dis. 90:941-945.

10. Isard, S. A., Gage, S. H., Comtois, P., and Russo, J. M. 2005. Principles of the atmospheric pathway for invasive species applied to soybean rust. BioScience 55:851-861.

11. Isard, S. A., Russo, J. M., and DeWolf, E. D. 2006. The establishment of a national Pest Information Platform for Extension and Education. Online. Plant Health Progress doi:10.1094/PHP-2006-0915-01-RV.

12. Jarvie, J. A. 2009. A review of soybean rust from a South African perspective. S. Afr. J. Sci. 105:103-108

13. Jurick, W. M., Narváez, D. F., Brennan, M. M., Harmon, C. L., Marois, J. J., Wright, D. L., and Harmon, P. F. 2008. Winter survival of the soybean rust pathogen, Phakopsora pachyrhizi, in Florida. Plant Dis. 92:1551-1558.

14. Marchetti, M. A., Melching, J. S., and Bromfield, K. R. 1976. The effect of temperature and dew period on germination and infection by urediniospores of Phakopsora pachyrhizi. Phytopathology 66:461-463.

15. McWilliams, D. A., Berglund, D. R., and Endres, G. J. 2004. Soybean 
Growth and Management Quick Guide. Online publication. NDSU Agriculture and University Extension. A-1174.

16. Melching, J. S., Dowler, W. M., Koogle, D. L., and Royer, M. H. 1989. Effect of duration, frequency, and temperature of leaf wetness periods on soybean rust. Plant Dis. 73:117-122.

17. Mueller, T. A., Miles, M. R., Hartman, G. L., O’Brien, G. K., Marois, J. J., and Wright, D. L. 2008. Evaluation of fungicides and fungicide timing for the control of soybean rust in northwest Florida, 2006. Plant Disease Management Reports (online). Report 2:FC086. DOI:10.1094/PDMR02. American Phytopathological Society, St. Paul, MN.

18. Narváez, D. F., Jurick, W. M., Marois, J. J., and Wright, D. L. 2010. Effects of surface wetness periods on development of soybean rust under field conditions. Plant Dis. 94:258-264.

19. Pan, Z., Yang, X. B., Pivonia, S., Xue, L., Pasken, R., and Roads, J. 2006. Long-term prediction of soybean rust entry into the continental United States. Plant Dis. 90:840-846.

20. Park, S., Chen, Z. Y., Chanda, A. K., Schneider, R. W., and Hollier, C. A. 2008. Viability of Phakopsora pachyrhizi urediniospores under simulated southern Louisiana winter temperature conditions. Plant Dis. 92:1456-1462.

21. Parry, D. W. 1990. Plant pathology in agriculture. Cambridge University Press, New York.

22. Sangawongse, P., Kittisin, S., and Nunthapun, M. 1977. Chemical control of soybean rust in Thailand. Thai. J. Agric. Sci. 10:1-8.

23. Schneider, R. W., Hollier, C. A., Whitam, H. K., Palm, M. E., McKemy, J. M., Hernandez, J. R., Levy, L., and DeVries-Paterson, R. 2005. First report of soybean rust caused by Phakopsora pachyrhizi in the continental United States. Plant Dis. 89:774.

24. Stovold, G. E., and Smith, H. J. P. 1991. The prevalence and severity of diseases in the coastal soybean crop of New South Wales. Aust. J. Exp. Agric. 31:545-550.

25. Vidhyasekaran, P. 2004. Concise Encyclopedia of Plant Pathology. Food Products Press and The Haworth Reference Press, Binghamton, NY.

26. Wright, D. L., Rich, J. R., Marois, J. J., Sprenkel, R. K., and Ferrell, J. A. 2002. Soybean Production in Florida. Electronic Data Information Source of UF/IFAS Extension (EDIS). SS-AGR-182. Online publication.

27. Yang, X. B., Dowler, W. M., and Tschanz, A. T. 1991. A simulation model for assessing soybean rust epidemics. J. Phytopathol. 133:187-200.

28. Yang, X. B., Tschanz, A. T., Dowler, W. M., and Wang, T. C. 1991. Development of yield loss models in relation to reductions of components of soybean infected with Phakopsora pachyrhizi. Phytopathology 81:1420-1426.

29. Yorinori, J. T., Paiva, W. M., Frederick, R. D., Costamilan, L. M., Bertagnolli, P. F., Hartman, G. L., Godoy, C. V., and Nunes-Junior, J. 2005. Epidemics of soybean rust (Phakopsora pachyrhizi) in Brazil and Paraguay from 2001 to 2003. Plant Dis. 89:675-677. 